\title{
Study on control mode of operation parameter in hydropower air chamber
}

\author{
Tingyu $\mathrm{Xu}^{1, \mathrm{a}}$ and Jian $\mathrm{Zhang}^{1}$ \\ ${ }^{1}$ College of Water Conservancy and Hydropower Engineering, Hoihai University, Jiangsu Nanjing, 210098, China
}

\begin{abstract}
This paper makes a deep analysis on PL control mode and static water level control mode, which could control operation parameters more conveniently and ensure safety and stability of hydropower water conveyance system. Considering the physical circumstance of monitoring parameters of the air chamber, the mathematic model of air chamber is built. On the basis of two basic criteria which are the maximum pressure at the end of spiral case and the down surge of the air chamber in hydraulic transient process, one hydropower station with air chamber is taken as an example. Determined by the effects of the upper reservoir water level on monitoring parameters, the allowable ranges of PL and air height could be consulted to control actuating and impeding the air compressor and the exhaust valve in an appropriate way. It is put forward that the maximum (minimum) product of the pressure and air height under dynamic initial condition, the maximum (minimum) air height under dynamic initial condition and static initial condition are determined by the criteria of down surge in the air chamber with large volume air (the criteria of the maximum pressure at the end of the spiral case with small volume air).
\end{abstract}

\section{Introduction}

In recent 40 years, several air chambers have been put into use at home and abroad in succession. With exploitation of hydroelectric energy in China, safe control of air chamber becomes a significantly important research. The operation mode of air chamber is taking advantage of actuating and impeding of air compressor and exhaust valve to supplement and let off air, which can control the air capacity and make sure of safe and stable operation of station. Concerning about selection of polytrophic exponent and calculation conditions, numerous researchers have had great achievements. X.H. Zhang et al [1] demonstrated that 1.4 polytrophic exponent was chosen to satisfy the requirement of small fluctuation stability and maximum pressure due to rejecting load. 1.0 polytrophic exponent was chosen to satisfy without gas leak. J. Zhang et al [2] put forward the theory of four specific processes combined with the gas characters of chamber in process of hydraulic transients and pointed that polytrophic exponent of gas would be larger than 1.4. 1.2 polytrophic exponent would also underestimate extreme pressure and surge wave, J.Y. Hu et al [3] presented that polytrophic exponent of gas exceeds the range of 1.0 1.4 for gas dynamic characteristic.

There are three operation control modes basically. C.Q. Qu et al [4] explained that every control modes have corresponding monitoring systems. PV/T control mode monitors pressure, volume and temperature. PV control mode monitors pressure and volume. Water level control mode only monitors water level. PV/T control mode modifies initial pressure and volume by temperature. PV control mode uses extreme value to control the air compressor and exhaust valve to satisfy the requirement of design in transient process, maintaining the value of PV and neglecting the change of temperature. J. Liu et al [5] introduced that PV control mode was utilized in Yesanhe air chamber in Hubei province. D.Y. Liu et al [6] proved that PV control mode could ensure the stable operation of Dagangou hydropower station combining practical experience. PV control mode has convenient operation especially when the exhaust valve needn't actuated and the air compressor ran unusually. Water level control mode gives advice on unified water level under stable operation to make sure safety requirement, concerning upstream water level and situation of the station. Z.Y. Peng et al [7] demonstrated that PV control mode which was usually put into use in practical air chamber didn't need frequently supplementing and giving off air like water level control mode without considering about gas leak. J.F. An et al [8] considered the influence gas leak and temperature's change having on safe control. Considering the actual change situation of monitoring parameters of air chamber, we analysed the mathematic model of air chamber and the extreme valve of surge wave and penstock pressure under no-friction system. The allowable range of PL and air height are determined by the effects of the upstream level on monitoring parameters, which can be consulted to control actuating and impeding the air compressor and the exhaust valve in an appropriate way, in order to make sure of security of water conveyance system.

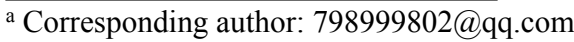




\section{Mathematical model and theory analysis}

\subsection{Basic model of the air chamber}

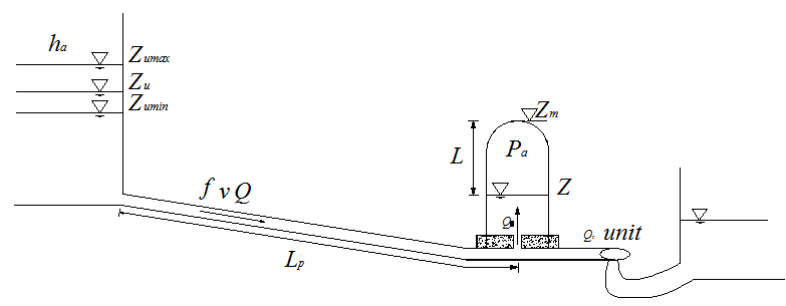

Figure 1. Water conveyance system of hydropower station with air chamber

Suppose that the air chamber is a cylinder, and the cross section remains unchanged with height. As a result, PV control mode means the same as PL control mode. Functions of the pressure and control parameters under statistic condition and stable condition are as follow:

$$
\begin{gathered}
Z_{u}+h_{a}=Z_{m}-L_{0}+P_{0} \\
P_{0} L_{0}=P_{a 0} L_{a 0}=C_{t 0} \\
Z_{u}+h_{a}=Z_{m}-L_{a 0}+P_{a 0}+\alpha Q^{2}
\end{gathered}
$$

In which $Z_{u}$ and $Z_{m}$ are upstream water level and crest elevation. $h_{a}$ is local atmosphere pressure. $P_{0}$ and $P_{a 0}$ are pressure under statistic and initial dynamic condition. $L_{0}$ and $L_{a 0}$ are air heights under statistic and initial dynamic condition. $\alpha$ and $Q$ are impedance coefficient and flow of the penstock.

According to (1), (2) and (3), initial dynamic water level function of air chamber can be concluded.

$$
L_{a 0}=Z_{m}-\frac{1}{2}\left[\left(Z_{u}+h_{a}-\alpha Q^{2}+Z_{m}\right)+\sqrt{\left(Z_{u}+h_{a}-\alpha Q^{2}+Z_{m}\right)^{2}-4 \times\left(\left(Z_{u}+h_{a}-\alpha Q^{2}\right) \times Z_{m}-C_{t 0}\right)}\right](4)
$$

Function (5) can be also get from (1) and (2).

$$
C_{t 0}=P_{0} L_{0}=\left[Z_{u}+h_{a}-\left(Z_{m}-L_{0}\right)\right] L_{0}=L_{0}^{2}+\left(Z_{u}+h_{a}-Z_{m}\right) L_{0}
$$

The relation between $C_{0}$ and $L_{0}$ is known because of monotonousness and concavityof functions:

$$
\begin{gathered}
\frac{\partial C_{t 0}}{\partial L_{0}}=2 L_{0}+\left(Z_{u}+h_{a}-Z_{m}\right)>0 \\
\frac{\partial^{2} C_{t 0}}{\partial L_{0}^{2}}=2>0
\end{gathered}
$$

$C_{t 0}$ is $L_{0}$ 's monotony increase by degrees concave function. When $L_{0}$ is higher, $C_{t 0}$ is larger and the amplification is larger. When $Z_{u}$ differs, there is a one-toone correspondence between $C_{t 0}$ and $L_{0}$, which is obtained by $Z_{u}$. Also, when $Z_{u}$ is fixed, the higher $L_{0}$ is, the larger $P_{0}$ is. The relationship between $Z_{u}$ and $L_{a 0}$ can be reached by function (2) and (3). $Z_{u}$ is $L_{a 0}$ 's monotony decrease function if $C_{t 0}$ and $\alpha Q^{2}$ are given, which means that the higher $L_{a 0}$ is, the smaller $P_{a 0}$ is and the lower $Z_{u}$ is.

The dynamic function, continuity function and gas function of air chamber in operation can be seen in function (8), (9) and (10).

$$
\begin{gathered}
Z_{u}+h_{a}-\alpha Q^{2}-\alpha_{0} Q_{s t}{ }^{2}-\left(Z_{m}-L_{a}\right)-P_{a}=\frac{L}{f g} \frac{d Q}{d t} \\
f v+F \frac{d L_{a}}{d t}=Q_{t} \\
P_{a} L_{a}{ }^{m}=P_{a 0} L_{a 0}{ }^{m}=C
\end{gathered}
$$

In which $P_{a}$ is dynamic pressure of air chamber. $L_{a}$ is dynamic gas height of air chamber. $\alpha_{0}$ is impedance coefficient of air chamber. $Q_{s t}$ and $Q_{t}$ are flow of air chamber and unit. $f$ and $F$ are cross sections of penstock and air chamber. $m$ is gas polytrophic exponent.

\subsection{Selection of gas polytrophic exponent}

Both function (2) and (10) should be satisfied when high pressure gas is in hydraulic transient process. $m$ is 1.0 with isothermal process, $\infty$ with isochoric process, 0.0 with isobaric process and 1.4 adiabatic process. Due to fast changes of air pressure and volume, the gas cannot exchange heat sufficiently, which means that $\mathrm{m}$ is between 1.0 and 1.4. It's significant to select the value of gas polytrophic exponent for it has a huge effect on the result.

The functions of the pressure at the bottom of the air chamber $\Delta H^{*}$, the surge range $\Delta Z^{*}$ and the steady section area $A_{s t}$ are as follows:

$$
\begin{gathered}
\Delta H^{*}=v_{0} \sqrt{\frac{L_{p} f}{g F}} \times \sqrt{\sigma} \\
\Delta Z^{*}=v_{0} \sqrt{\frac{L_{p} f}{g F}} / \sqrt{\sigma} \\
A_{s t} \geq K \times \frac{L_{p} f}{2 \alpha g\left(H_{0}-2 h_{w m}\right)} \times \sigma \\
\sigma=1+m\left(\frac{Z_{u}-Z_{m}+h_{\mathrm{a}}-\alpha Q_{0}{ }^{2}}{L_{a 0}}+1\right)
\end{gathered}
$$

It is shown by function (11), (12), (13) and (14), the constant is directly proportional to the initial height of the chamber and proportional to gas polytrophic exponent. What's more, the higher the air is, the smaller the gas polytrophic exponent is, the larger the wave is, and the lower the water level of the air chamber is. The larger the pressure of the pipeline and the chamber is, the larger the cross section is conversely. As a result, the largest height of the initial air is determined by the lowest wave of the chamber when $\mathrm{m}$ is 1.0 for security. The smallest height of the air is determined by the largest pressure of the system and the stability of the chamber.

\subsection{Determination of the PV}

As for the PV control mode, the variation of the PV could be get by the trial calculation of the initial water level of the chamber in static condition. According to previous analysis, the variation of dynamic water level and $\left[L_{a 0}\right]_{\max }$ could be determined by the control value of the lowest wave under condition of large volume air with the lowest water level of fore bay and the normal tail water level, and the variation of dynamic water level and 
$\left[L_{a 0}\right]_{\min }$ could be determined by the control value of the largest pressure under condition of small volume air with the highest water level of fore bay and the normal tail water. Then the inequality could be get by (15).

$$
\left[P_{a 0} L_{a 0}\right]_{\min } \leq\left[P_{a 0} L_{a 0}\right] \leq\left[P_{a 0} L_{a 0}\right]_{\max }
$$

Concerning the practical situation of the project, $\left[P_{a 0} L_{a 0}\right]_{\min }$, the minimum product of the pressure and air height under dynamic initial condition could be used to calculate pressure condition when $\mathrm{m}$ is 1.4. $\left[P_{a 0} L_{a 0}\right]_{\max }$, the maximum product of the pressure and air height under dynamic initial condition could be used to calculate wave condition when $\mathrm{m}$ is 1.0 for security.

\subsection{Determination of air height in static condition}

Transforming the static height range $\left(a_{1}, b_{1}\right)$ under condition of large volume air into the other under condition of small volume air $\left(a_{1}{ }^{\prime}, b_{1}{ }^{\prime}\right)$ by the PL value of small volume air which meets the requirement, functions are as follows by (16) and (17). The intersection of $\left(a_{1}{ }^{\prime}, b_{1}{ }^{\prime}\right)$ and $\left(c_{1}, d_{1}\right)$, which is actual static height range under condition of small volume air, is $(\mathrm{m}, \mathrm{n})=\left(c_{1}, b_{1}{ }^{\prime}\right)$.

$$
\begin{gathered}
{\left[Z_{u \text { max }}+h_{a}-\left(Z_{m}-a_{1}^{\prime}\right)\right] a_{1}^{\prime}=\left[Z_{u \text { min }}+h_{a}-\left(Z_{m}-a_{1}\right)\right] a_{1}} \\
{\left[Z_{u \max }+h_{a}-\left(Z_{m}-b_{1}^{\prime}\right)\right] b_{1}^{\prime}=\left[Z_{u \min }+h_{a}-\left(Z_{m}-b_{1}\right)\right] b_{1}=\left[P_{a 0} L_{a 0}\right]_{\max }}
\end{gathered}
$$

Transforming the static height range $\left(a_{1}, b_{1}\right)$ under condition of small volume air into the other under condition of large volume air $\left(a_{1}{ }^{\prime}, b_{1}{ }^{\prime}\right)$ by the PL value of large volume air which meets the requirement, functions are as follows by (18) and (19). The intersection of $\left(c_{1}{ }^{\prime}, d_{1}{ }^{\prime}\right)$ and $\left(a_{1}, b_{1}\right)$, which is actual static height range under condition of large volume air, is $(\mathrm{p}, \mathrm{q})=\left(c_{1}^{\prime}, b_{1}\right)$.

$$
\begin{gathered}
{\left[Z_{u \min }+h_{a}-\left(Z_{m}-c_{1}^{\prime}\right)\right] c_{1}^{\prime}=\left[Z_{u \max }+h_{a}-\left(Z_{m}-c_{1}\right)\right] c_{1}=\left[P_{a 0} L_{a 0}\right]_{\min }(18)} \\
{\left[Z_{u \min }+h_{a}-\left(Z_{m}-d_{1}^{\prime}\right)\right] d_{1}^{\prime}=\left[Z_{u \max }+h_{a}-\left(Z_{m}-d_{1}\right)\right] d_{1} \text { (19) }} \\
\text { The intersection of }\left(c_{1}, b_{1}{ }^{\prime}\right) \text { and }\left(c_{1}{ }^{\prime}, b_{1}\right) \text { is } \\
\left(\left[L_{0}\right]_{\min },\left[L_{0}\right]_{\max }\right)=\left(c_{1}^{\prime}, b_{1}{ }^{\prime}\right) .
\end{gathered}
$$

\subsection{Control mode of air chamber}

Control mode of air chamber is to control the state parameter of the air in chamber by actuating or impeding the air compressor or the exhaust valve when the monitor parameter gets to the extreme value set before, in order to ensure the safety of pipeline and the air chamber during hydraulic transients. Thus, it is key for safe control of the air chamber to determine the extreme value of the monitor parameter according to the actuating and impeding of the air compressor and the exhaust valve under different modes.

Suppose that the temperature is unchanged during operation, the value of $\mathrm{PV}$ is constant within the range of PL. When the air height falls below $\left[L_{a 0}\right]_{\min }$, the unit shall be stopped first and the air compressor shall be actuated then, which makes water level drop at the same time. The air compressor shall be impeded when the air height is not higher than $\left[L_{a 0}\right]_{\max }$. When the air height increases over $\left[L_{a 0}\right]_{\max }$, the unit shall be stopped first and the exhaust valve shall be actuated then, which makes water level rise at the same time. The exhaust valve shall be impeded when the air height is not lower than $\left[L_{a 0}\right]_{\min }$.

Suppose that the temperature is unchanged and gas leak does not happen, the static air height should be ensured within the range of $\left(\left[L_{0}\right]_{\min },\left[L_{0}\right]_{\max }\right)$. When the air height monitored falls below $\left[L_{a 0}\right]_{\min }$, the unit shall be stopped first and the air compressor shall be actuated then, which makes water level drop at the same time. The air compressor shall be impeded when the air height is not higher than $\left[L_{a 0}\right]_{\max }$. When the air height increases over $\left[L_{a 0}\right]_{\max }$, the unit shall be stopped first and the exhaust valve shall be acutated then, which makes water level rise at the same time. The exhaust valve shall be impeded when the air height is not lower than $\left[L_{a 0}\right]_{\min }$.

Air chamber control mode is shown in fig.2.

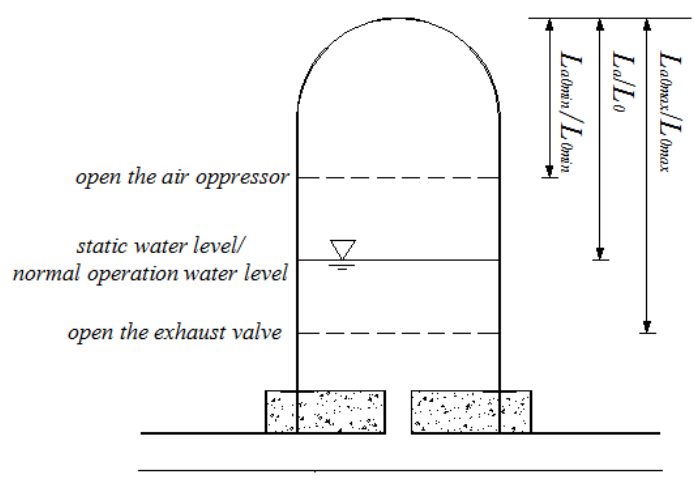

Figure 2. Air chamber safe control mode.

\section{Case}

\subsection{Project description}

Take one hydropower station with an air chamber in the world as an example. The rated water head of a power station is $84.4 \mathrm{~m}$ with one tunnel for two units. The distance between the upper reservoir and the air chamber is $2047.97 \mathrm{~m}$. The distance between the air chamber and the unit is $77.58 \mathrm{~m}$. The distance between the unit and the lower reservoir is $4.33 \mathrm{~m}$. The reference flow is $2.3 \mathrm{~m}^{3} / \mathrm{s}$ for each unit and the installed capacity is $2 \times 1.5 \mathrm{MW}$. The cross section of the air chamber is round with a diameter of $7.6 \mathrm{~m}$. The diameter of the impedance hole is $1.0 \mathrm{~m}$. The air chamber is $14 \mathrm{~m}$ in height, whose evaluation of the chamber bottom is $371.69 \mathrm{~m}$, and the top is $385.69 \mathrm{~m}$. The one-stage straight line closing regularity of $5 \mathrm{~s}$ is selected for the closing time of guide vanes. The one-stage straight line opening regularity of $30 \mathrm{~s}$ is selected for the opening time of guide vanes. The atmospheric pressure is $10 \mathrm{~m}$. Hydropower station with diversion system layout is shown by fig. 3 .

The control criteria must be taken into account when the allowable ranges of water level in fore bay and air chamber parameters of fore bay is determined: (1) the maximum pressure value of spiral case $\leq 126.25 \mathrm{~m}$. (2) 
The down surge of the air chamber $\geq 374.69 \mathrm{~m}$. The calculation conditions are shown is Table 1 .

Table 1. Calculation conditions

\begin{tabular}{|c|c|c|c|c|}
\hline $\begin{array}{c}\text { Conditio } \\
\mathrm{n}\end{array}$ & $\begin{array}{l}\text { Water level } \\
\text { of fore bay }\end{array}$ & $\begin{array}{c}\text { Tail } \\
\text { water } \\
\text { level }\end{array}$ & $\begin{array}{l}\text { Change } \\
\text { of unit }\end{array}$ & $\begin{array}{c}\text { Gas } \\
\text { polytrophi } \\
\text { c exponent }\end{array}$ \\
\hline A1 & & \multirow{4}{*}{370.67} & \multirow{2}{*}{$1-2-0$} & 1.4 \\
\hline A2 & $Z_{u}$ & & & 1 \\
\hline B1 & \multirow{2}{*}{$Z_{u \max }=469.213$} & & \multirow{2}{*}{$2-0-1$} & 1.4 \\
\hline B2 & & & & 1 \\
\hline
\end{tabular}

\subsection{Determination of the extreme value of} $\left[P_{a 0} L_{a 0}\right]$

\subsubsection{Determination of $\left[P_{a 0} L_{a 0}\right]_{\min }$}

According to previous analysis, $\left[P_{a 0} L_{a 0}\right]_{\min }$ is decided by the largest pressure of the pipeline. The maximum pressure of water conveyance system occurs at the end of spiral case under A2 condition, combining the practical situation. Initial dynamic air height, absolute pressure and the allowable extreme value of PL could be get through trial calculation of static water level of air chamber under A2 condition, satisfying the maximum pressure of the pipeline. The result is shown in Table 2.

Table 2. Result of $\left[P_{a 0} L_{a 0}\right]_{\min }$

\begin{tabular}{|c|c|c|c|c|c|}
\hline $\begin{array}{c}\text { Static } \\
\text { initial } \\
\text { water } \\
\text { level (m) }\end{array}$ & $\begin{array}{c}\text { Initial } \\
\text { dynamic } \\
\text { water } \\
\text { level (m) }\end{array}$ & $\begin{array}{c}\text { Max. } \\
\text { pressure } \\
\text { at the end } \\
\text { of spiral } \\
\text { case(m) }\end{array}$ & $\begin{array}{c}\text { Dynamic } \\
\text { initial } \\
\text { absolute } \\
\text { air } \\
\text { pressure } \\
(\mathrm{m})\end{array}$ & $\begin{array}{c}\text { Dynamic } \\
\text { initial air } \\
\text { height } \\
(\mathrm{m})\end{array}$ & {$\left[P_{a 0} L_{a 0}\right]_{\min }$} \\
\hline 377.70 & 377.40 & 126.64 & 97.80 & 8.29 & 811.09 \\
\hline $\mathbf{3 7 7 . 5 5}$ & $\mathbf{3 7 7 . 2 4}$ & $\mathbf{1 2 6 . 2 3}$ & $\mathbf{9 7 . 9 6}$ & $\mathbf{8 . 4 5}$ & $\mathbf{8 2 7 . 5 4}$ \\
\hline 377.00 & 376.67 & 124.88 & 98.52 & 9.02 & 888.23 \\
\hline 376.67 & 376.33 & 124.13 & 98.86 & 9.36 & 924.94 \\
\hline 376.65 & 376.31 & 124.09 & 98.88 & 9.38 & 927.17 \\
\hline
\end{tabular}

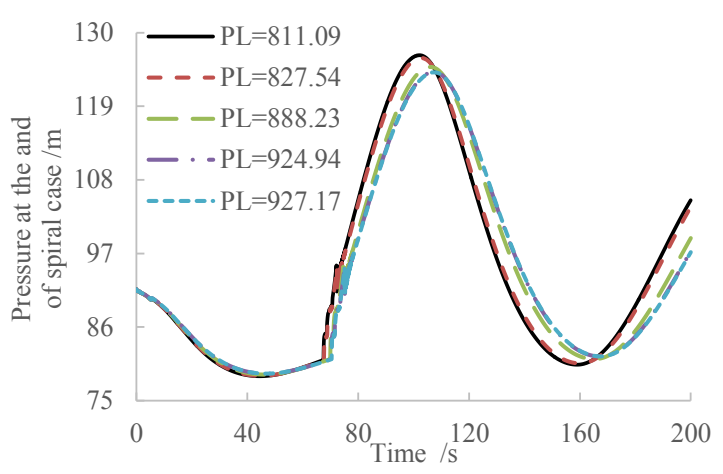

Figure 3. Varying curve of the pressure at the end of spiral case with time under different PL

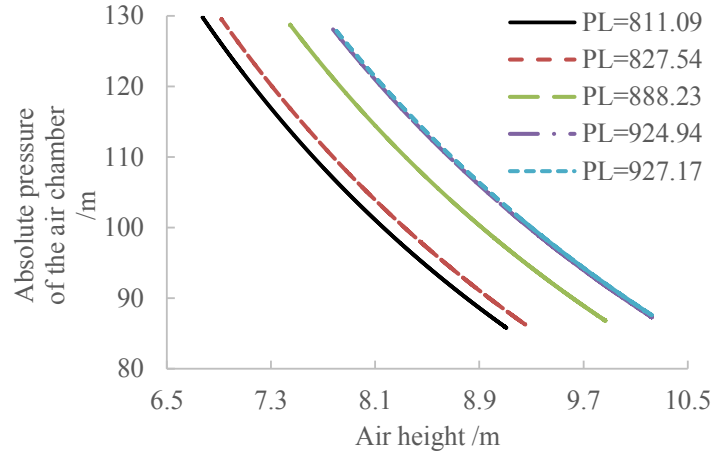

Figure 4. Varying curve of absolute pressure with height in the surge chamber under different PL

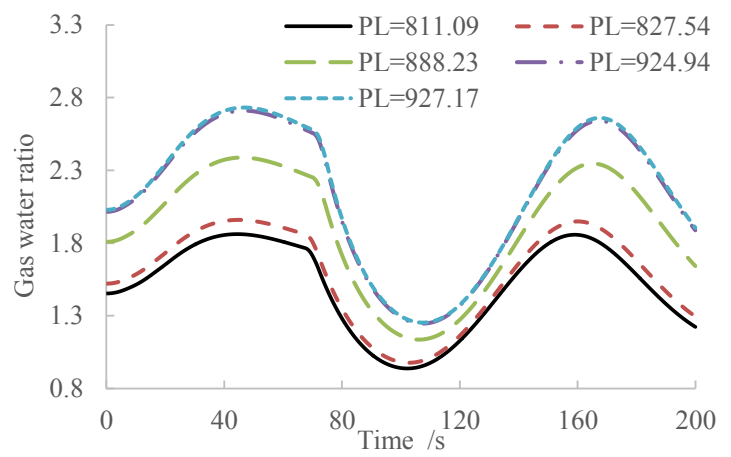

Figure 5. Varying curve of gas water ratio with time under different PL

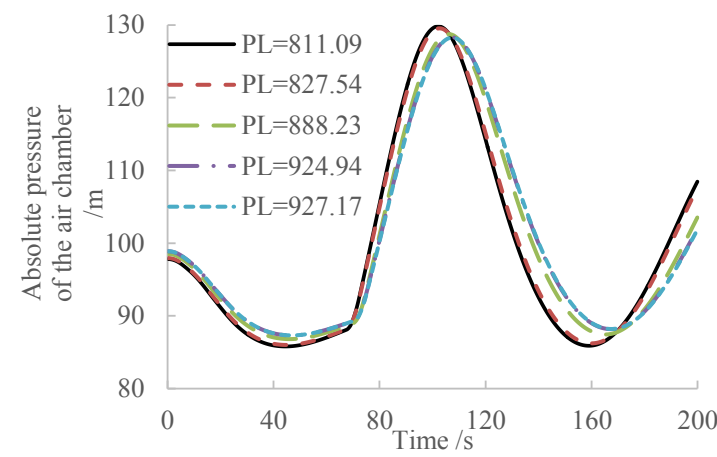

Figure 6. Varying curve of absolute pressure with time in the surge chamber under different PL

It is illustrated from the result that the higher the static water level of air chamber is, the higher the initial dynamic water level is (the smaller the initial dynamic air height is), the smaller the initial dynamic absolute pressure is, the smaller $\left[P_{a 0} L_{a 0}\right]_{\min }$ is, the larger the maximum pressure at the end of spiral case is, and the earlier it happens, the higher the lowest wave of the air chamber is. Gas water ratio of the air chamber increases first and then drops periodically. The larger $\left[P_{a 0} L_{a 0}\right]_{\min }$ is, the larger the wave range is. The variation trend with height of the absolute pressure in the surge chamber is the same under different PL. When $\left[P_{a 0} L_{a 0}\right]_{\min }=827.54 \mathrm{~m}^{2}$, Maximum pressure at the end of spiral case is $126.23 \mathrm{~m}$, satisfying the requirement of $126.25 \mathrm{~m}$. In that case, the minimum of PL is $827.54 \mathrm{~m}^{2}$ under this mode.

3.2.2 Determination of $\left[P_{a 0} L_{a 0}\right]_{\max }$ 
According to previous analysis, $\left[P_{a 0} L_{a 0}\right]_{\max }$ is decided by the lowest wave of air chamber. The down surge of air chamber occurs in condition B1, combining the practical situation. Initial dynamic air height, absolute pressure and the allowable extreme value of PL could be get through trial calculation of static water level of air chamber under B1 condition, satisfying the down surge of the air chamber. The result is shown in Table 3.

Table 2. Result of $\left[P_{a 0} L_{a 0}\right]_{\max }$

\begin{tabular}{|c|c|c|c|c|c|}
\hline $\begin{array}{c}\text { Static } \\
\text { initial } \\
\text { water } \\
\text { level (m) }\end{array}$ & $\begin{array}{c}\text { Initial } \\
\text { dynamic } \\
\text { water } \\
\text { level (m) }\end{array}$ & $\begin{array}{c}\text { Max. } \\
\text { pressure } \\
\text { at the end } \\
\text { of spiral } \\
\text { case(m) }\end{array}$ & $\begin{array}{c}\text { Dynamic } \\
\text { initial } \\
\text { absolute } \\
\text { air } \\
\text { pressure } \\
(\mathrm{m})\end{array}$ & $\begin{array}{c}\text { Dynamic } \\
\text { initial air } \\
\text { height } \\
(\mathrm{m})\end{array}$ & {$\left[P_{a 0} L_{a 0}\right]_{\max }$} \\
\hline 377.80 & 376.84 & 375.89 & 89.70 & 8.85 & 793.92 \\
\hline 377.00 & 375.96 & 375.02 & 90.58 & 9.73 & 881.37 \\
\hline 376.79 & 375.73 & 374.81 & 90.81 & 9.96 & 904.53 \\
\hline $\mathbf{3 7 6 . 6 8}$ & $\mathbf{3 7 5 . 6 1}$ & $\mathbf{3 7 4 . 7 0}$ & $\mathbf{9 0 . 9 3}$ & $\mathbf{1 0 . 0 8}$ & $\mathbf{9 1 6 . 7 1}$ \\
\hline 376.66 & 375.59 & 374.68 & 90.95 & 10.10 & 918.92 \\
\hline
\end{tabular}

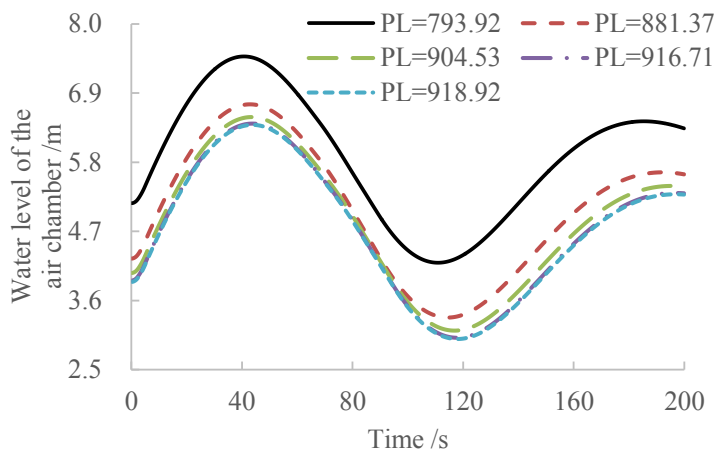

Figure 7. Varying curve of the pressure at the end of spiral case with time under different PL

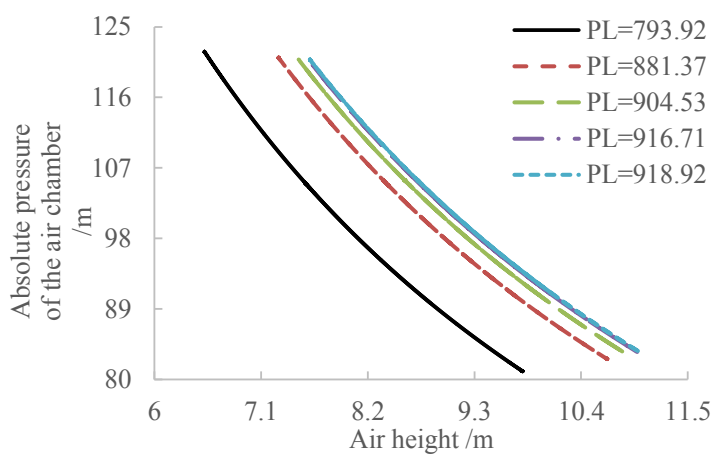

Figure 8. Varying curve of absolute pressure with height in the surge chamber under different PL

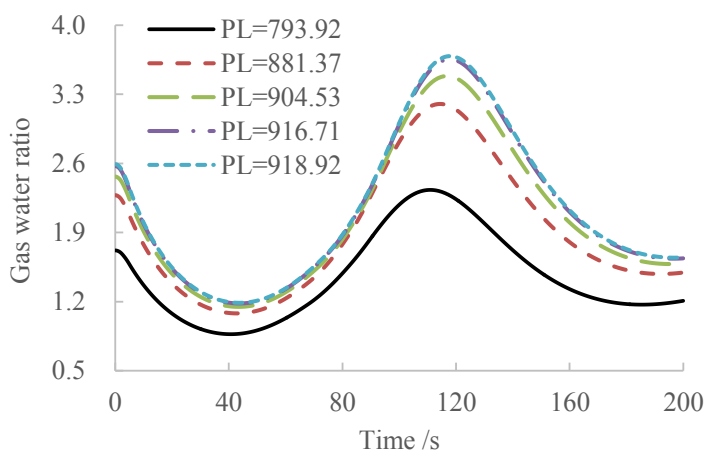

Figure 9. Varying curve of gas water ratio with time under different PL

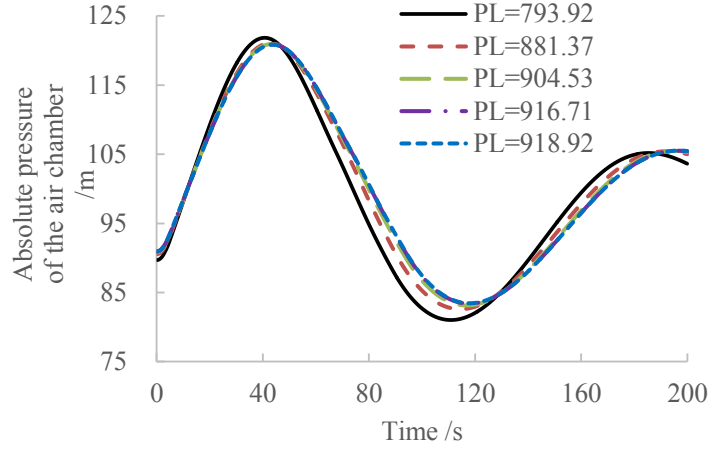

Figure 10. Varying curve of absolute pressure with time in the surge chamber under different PL

It is illustrated from the result that the higher the static water level of air chamber is (the smaller the initial static air height is), the higher the initial dynamic water level is (the smaller the initial dynamic air height is), the smaller the initial dynamic absolute pressure is, the smaller $\left[P_{a 0} L_{a 0}\right]_{\max }$ is, the larger the maximum pressure at the end of spiral case is, the larger the wave range of the air chamber is. Gas water ratio of the air chamber drops first and then increases periodically. The larger $\left[P_{a 0} L_{a 0}\right]_{\max }$ is, the larger the wave range is. The variation trend with height of the absolute pressure in the surge chamber is the same under different $\left[P_{a 0} L_{a 0}\right]_{\max }$. When $\left[P_{a 0} L_{a 0}\right]_{\max }=916.71 \mathrm{~m}^{2}$, the down surge of the air chamber is $374.70 \mathrm{~m}$, satisfying the requirement that safe depth of the water is $3 \mathrm{~m}$ higher. In that case, the maximum of PL is $916.71 \mathrm{~m}^{2}$ under this mode.

\subsubsection{Trail calculation results of Condition A1 and Condition B2}

Trail calculation results of Condition A1 and Condition B2 are as follows:

Table 4. Result of Condition B2

\begin{tabular}{|c|c|c|c|c|c|}
\hline $\begin{array}{c}\text { Static } \\
\text { initial } \\
\text { water } \\
\text { level (m) }\end{array}$ & $\begin{array}{c}\text { Initial } \\
\text { dynamic } \\
\text { water } \\
\text { level (m) }\end{array}$ & $\begin{array}{c}\text { Max. } \\
\text { pressure } \\
\text { at the end } \\
\text { of spiral } \\
\text { case(m) }\end{array}$ & $\begin{array}{c}\text { Dynamic } \\
\text { initial } \\
\text { absolute } \\
\text { air } \\
\text { pressure } \\
(\mathrm{m})\end{array}$ & $\begin{array}{c}\text { Dynamic } \\
\text { initial air } \\
\text { height (m) }\end{array}$ & PL \\
\hline 377.70 & 376.77 & 376.65 & 90.91 & 8.92 & 811.09 \\
\hline 377.55 & 377.24 & 375.64 & 91.07 & 9.09 & 827.54 \\
\hline 377.00 & 376.00 & 375.06 & 91.67 & 9.69 & 888.23 \\
\hline $\mathbf{3 7 6 . 6 7}$ & $\mathbf{3 7 5 . 6 4}$ & $\mathbf{3 7 4 . 7 0}$ & $\mathbf{9 2 . 0 4}$ & $\mathbf{1 0 . 0 5}$ & $\mathbf{9 2 4 . 9 4}$ \\
\hline 376.65 & 375.62 & 374.68 & 92.06 & 10.07 & 927.17 \\
\hline
\end{tabular}

Table 4. Result of Condition A1

\begin{tabular}{|c|c|c|c|c|c|}
\hline $\begin{array}{c}\text { Static } \\
\text { initial } \\
\text { water } \\
\text { level (m) }\end{array}$ & $\begin{array}{c}\text { Initial } \\
\text { dynamic } \\
\text { water } \\
\text { level (m) }\end{array}$ & $\begin{array}{c}\text { Max. } \\
\text { pressure } \\
\text { at the end } \\
\text { of spiral } \\
\text { case(m) }\end{array}$ & $\begin{array}{c}\text { Dynamic } \\
\text { initial } \\
\text { absolute } \\
\text { air } \\
\text { pressure } \\
\text { (m) }\end{array}$ & $\begin{array}{c}\text { Dynamic } \\
\text { initial air } \\
\text { height (m) }\end{array}$ & PL \\
\hline $\mathbf{3 7 7 . 8 0}$ & $\mathbf{3 7 7 . 4 9}$ & $\mathbf{1 2 6 . 2 4}$ & $\mathbf{9 6 . 8 6}$ & $\mathbf{8 . 2 0}$ & $\mathbf{7 9 3 . 9 2}$ \\
\hline 377.00 & 376.67 & 124.20 & 97.68 & 9.02 & 881.37 \\
\hline 376.79 & 376.45 & 123.70 & 97.90 & 9.24 & 904.53 \\
\hline 376.68 & 376.34 & 123.47 & 98.01 & 9.35 & 916.71 \\
\hline 376.66 & 376.32 & 123.42 & 98.03 & 9.37 & 918.92 \\
\hline
\end{tabular}




\subsection{Analysis of results}

\subsubsection{PL control mode}

As for PL control mode of the air chamber, the range of PL could be concluded through trial calculation of the initial water level under static condition. $\left[L_{a 0}\right]_{\max }$, the maximum of air height under dynamic condition could be calculated according to the down surge of the air chamber with large volume air. $\left[L_{a 0}\right]_{\min }$, the minimum of air height under dynamic condition could be calculated according to the maximum pressure at the end of spiral case with small volume air. And it also can be get that $\left[P_{a 0} L_{a 0}\right]_{\max }=916.71 \mathrm{~m}^{2}\left[P_{a 0} L_{a 0}\right]_{\min }=827.54 \mathrm{~m}^{2}$.

It is shown by Table 4 and Table 5 that the result concluded by Condition B2 meeting criteria of down surge $\left(\mathrm{PL}=924.94 \mathrm{~m}^{2}\right)$ is more than the maximum of the PL value $\left(916.71 \mathrm{~m}^{2}\right)$ with small volume air and that the result concluded by Condition B2 meeting criteria of maximum pressure $\left(\mathrm{PL}=793.92 \mathrm{~m}^{2}\right)$ is less than the minimum of the PL value $\left(827.54 \mathrm{~m}^{2}\right)$ with large volume air, which makes the conclusion prove to be true that PL should be calculated using maximum pressure with small volume air and using down surge with large volume air.

In general, when the PV control mode is used, PL must be within the range from $827.54 \mathrm{~m}^{2}$ to $916.71 \mathrm{~m}^{2}$. If $\mathrm{PL}$ is below $827.54 \mathrm{~m}^{2}$ during the operation when there is a leak, the compressed air shall be charged into the chamber, after which PL shall not exceed $916.71 \mathrm{~m}^{2}$. Similarly, if PL is over $916.71 \mathrm{~m}^{2}$ during the operation, the air shall be exhausted out of the chamber, after which PL shall not be less than $916.71 \mathrm{~m}^{2}$.

\subsubsection{Water level control mode}

Synthesizing Condition A1, Condition A2, Condition B1 and Condition B2, the dynamic and static water level range of the air chamber could be concluded by the criteria with large volume air. The static water level range of the air chamber is $(376.68,377.80)$ and the range of static air height is $(7.89,9.01)$, which has $1.12 \mathrm{~m}$ in variable range. The dynamic water level range of the air chamber is $(375.61,377.49)$ and the range of dynamic air height is $(8.20,10.08)$, which has $1.88 \mathrm{~m}$ in variable range. Comparatively, the dynamic and static water level range of the air chamber could be concluded by the criteria with small volume air. The static water level range of the air chamber is $(376.67,377.55)$ and the range of static air height is $(8.14,9.02)$, which has $0.88 \mathrm{~m}$ in variable range. The dynamic water level range of the air chamber is $(375.64,377.24)$ and the range of dynamic air height is $(8.45,10.05)$, which has $1.60 \mathrm{~m}$ in variable range.

Transforming the static height range with large volume air into the other with small volume air by the PL value of small volume air which meets the requirement, the range is substituted into function (13) and (14). The intersection of $(7.83,8.95)$ and the actual static height range under condition of small volume air is $(8.14,8.95)$ with a variable range of $0.81 \mathrm{~m}$.
Transforming the static height range with small volume air into the other with large volume air by the PL value of large volume air which meets the requirement, the range is substituted into function (15) and (16). The intersection of $(8.20,9.08)$ and the actual static height range under condition of large volume air is $(8.20,9.01)$. The intersection of these two conditions is $(8.20,8.95)$.

In consequence, supposed that without considering about gas leak and the change of temperature, static air height is ensured between $(8.20,8.95)$ under static condition. When the monitor water level of the air chamber is higher than $377.49 \mathrm{~m}$, the air compressor shall be opened to compensate air into the chamber, after which the water level is not lower than $376.74 \mathrm{~m}$. If the monitor water level of the air chamber is lower than 376.74 , the exhaust valve shall be opened to let out air, after which the water level is not higher than $377.24 \mathrm{~m}$.

\subsubsection{Comparative analysis}

Compared with PV control mode, water level control mode should only ensure the static water level is within the range of the fixed one, and monitor one parameter. However, the range is so small that the frequency of making up air is fairly high. In conclusion, PL control mode should be used in this power station with an air chamber.

It is also concluded that there is a one-to-one correspondence with the change of upper reservoir water level not only between $\left[L_{a 0}\right]_{\min }$ and $\left[P_{a 0} L_{a 0}\right]_{\min }$ with small volume air, but also between $\left[L_{a 0}\right]_{\max }$ and $\left[P_{a 0} L_{a 0}\right]_{\max }$ with large volume air, which means:

$$
\begin{aligned}
& {\left[P_{a 0} L_{a 0}\right]_{\min }=P_{a 0} \times\left[L_{a 0}\right]_{\min }} \\
& {\left[P_{a 0} L_{a 0}\right]_{\max }=P_{a 0} \times\left[L_{a 0}\right]_{\max }}
\end{aligned}
$$

Varying curve of absolute pressure in the surge chamber and the pressure at the end of spiral case with time under different PL and varying curve of air height and the depth of water in the surge chamber with time under different PL of Condition A1 and Condition B1 are shown in Fig. 11 12 when static water level is $377 \mathrm{~m}$. Thus, with the same static water level and different upper reservoir water levels have an influence on the pressure at the spiral case and absolute pressure of the air chamber for one work condition. The trend of absolute pressure in the surge chamber and the pressure at the end of spiral case with time under different PL are similar, and that with small volume air is larger than that with large volume air. 


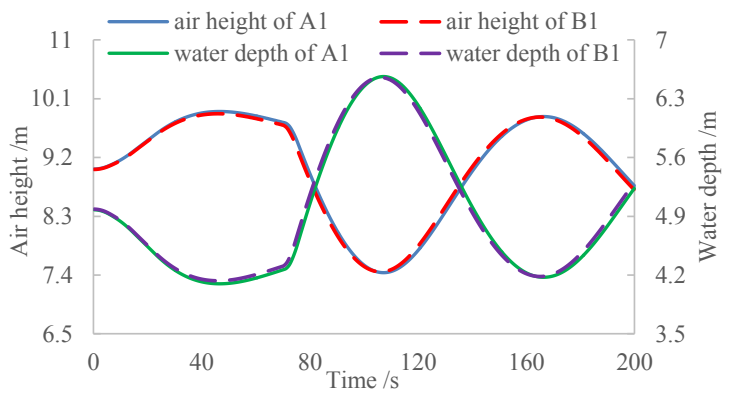

Figure 11. Varying curve of absolute pressure in the surge chamber and the pressure at the end of spiral case with time under different PL

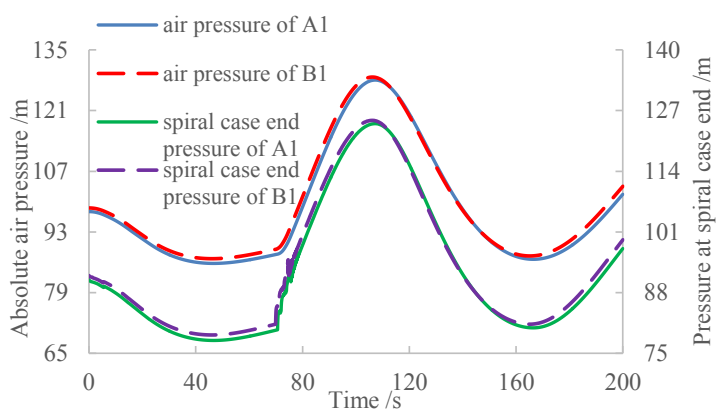

Figure 12. Varying curve of air height and the depth of water in the surge chamber with time under different PL

\section{Conclusion}

To sum up, the actual PL and the static water level during operation should be within the range of the suggested one combining with safe and steady operation of power station with an air chamber. The ranges of PL and the water level are get based on the factor of upper reservoir water level. $\left[P_{a 0} L_{a 0}\right]_{\max },\left[L_{a 0}\right]_{\max }$ and $\left[L_{0}\right]_{\max }$ are determined by the criteria of down surge in the air chamber with large volume air, while $\left[P_{a 0} L_{a 0}\right]_{\min }$, $\left[L_{a 0}\right]_{\min }$ and $\left[L_{0}\right]_{\min }$ are determined by the criteria of the maximum pressure at the end of the spiral case with small volume air. Compared with PV control mode, water level control mode should only ensure the static water level is within the range of the fixed one and monitor one parameter. However, it is quite a difficulty in controlling the parameter for the frequency of making up air is fairly high when the range is so small that. PL control mode should be used more often in hydropower station with an air chamber.

\section{Acknowledgement}

The study is financially supported by National Key R\&D Program of China (2016YFC0401810) and the Fundamental Research Funds for the Central Universities (Grant No. 2016B10814). The support is gratefully acknowledged.
1. X.H. Zhang, Z.F. Zhao and Y.H. Zhang, Study on Wave Calculation of an Air Cushion Surge Chamber, 70-73, (2009)

2. J. Zhang, L.S. Suo, Y. Zheng, D.Y. Liu, Study on gas characters of air-cushioned surge tank, Journal of Hydroelectric Engineering, 23, 97-101, (2004)

3. J.Y. Hu, J. Zhang, Y. Zheng, L.S. Suo, Study on operation characteristics of air cushion surge chamber, 99-102, (2007)

4. C.Q. Ou, D.Y. Liu and L.H. Li, Research on Dynamic Properties of Long Pipeline Monitoring System of Air Cushion Surge Chamber, in AsiaPacific Power and Energy Engineering Conference,108-111,(2009)

5. J. Liu, C.B. Qin, B. Niu, P.F. Sheng, Operation parameters of air-cushion surge chamber for Yesanhe Hydropower Station and their control method, Water Resources and Hydropower Engineering, 47, 9-12,( 2016)

6. D.Y. Liu, L.S. Suo, B. Li, C.B. Li, J. Zhang, Hydraulic characteristics and operation control of air-cushioned surge tank of Dagangou hydropower plant. Journal of Hydroelectric Engineering, 95-100, (2003)

7. Z.Y. Peng, J.D. Yang, W.C. Guo, Simulation of water level and air pressure inside the air cushion surge chamber under steady flow condition, Chinese Journal of Hydrodynamics, 31, 239-244, (2016)

8. J.F. An, J. Zhang, A. Hazrati, Safe control of air cushion surge chambers in hydropower systems. SCIENTIA IRANICA, 20, 1605-1611, (2013)

\section{References}

